\title{
A RESERVA BIOLÓGICA DE TINGUÁ (RJ) E A COMUNIDADE DO ENTORNO: UMA ANÁLISE DA RELAÇÃO A PARTIR DO CONCEITO DE PERCEPÇÃO AMBIENTAL
}

\author{
Sílvia Maria Varela ${ }^{1}$ \\ Andréia Lopes ${ }^{2}$ \\ Márcia Conceição Ferreira ${ }^{3}$ \\ Monika Richter ${ }^{4}$
}

\section{Resumo}

O objetivo deste artigo trata da Percepção Ambiental (PA) dos moradores do entorno da Reserva Biológica do Tinguá, localizada no centro-sul do estado do Rio de Janeiro, visando fornecer subsídios ao processo de gestão e manejo da Unidade de Conservação (UC). Esta categoria não permite visitação e nem atividades de lazer em seu interior o que tem gerado alguns conflitos junto aos moradores do entorno. Visando o embasamento teórico-conceitual relacionado à abordagem da $\mathrm{PA}$, realizou-se ampla pesquisa bibliográfica, constatando ser $\mathrm{Yu}$ Fu Tuan, e no Brasil a Geógrafa Humanista Livia de Oliveira, os precursores na temática. Também foram aplicados questionários semiestruturados para avaliar três grandes blocos: perfil dos moradores, conhecimento sobre a Reserva e expectativas relacionadas ao lugar. No total foram entrevistadas 62 pessoas e as falas mais frequentes foram sobre os problemas decorrentes do lixo, falta de fiscalização e a vontade de permanecerem na região. Conclui-se que os moradores percebem a importância e a influência da UC para a sua qualidade de vida, mas não compreendem as diferenças entre as esferas de gestão, pois ressaltam como principais problemas aspectos relacionados à infraestrutura de competência do município como coleta de lixo, educação e saúde.

Palavras-chave: Reserva biológica; topofilia; percepção ambiental.

\begin{abstract}
This paper deals with the Environmental Awareness (PA) of the surrounding residents of Tinguá Biological Reserve, located in the central-southern state of Rio de Janeiro, to provide input to the management of the Conservation Unit (CU). This category does not allow visitation, and even leisure activities inside which has generated some conflicts with the surrounding residents. Aiming at the theoretical-conceptual approach related to the PA, held extensive literature search, finding be $\mathrm{Yu} F u$ Tuan, and the brazilian humanist geographer Lívia de Oliveira, the forerunners in the theme. Semi-structured questionnaires were also applied to assess three major blocks: profile of residents, knowledge about the Reserve and expectations related to the place. In total 62 people were interviewed and the lines were more frequent on the problems of garbage, lack of supervision and the willingness to remain in the region. It is concluded that residents realize the importance and influence of UC for its quality of life, but do not understand the differences between the spheres of management, as emphasized that the

\footnotetext{
${ }^{2}$ Graduanda do Turismo Bacharelado UFRRJ/IM e Pesquisadora FAPERJ - andreialopes.stellet@ hotmail.com

${ }^{3}$ Graduanda do Turismo Bacharelado UFRRJ/IM - mconceicao@ hotmail.com

${ }^{4}$ Prof. Dra. De Geografia do Departamento de Educação e Sociedade UFRRJ/IM - mrichter84@hotmail.com
}

${ }^{1}$ Graduanda Geografia UFRRJ/IM e Pesquisadora de Iniciação Cientifica pelo CNPq - bj.silvia@ hotmail.com.br
\end{abstract}


main problems were related to infrastructure aspects of competence of the municipality such as garbage collection, education and health.

Keywords: Biological reserve; topophilia; environmental perception.

\section{Introdução}

A Reserva Biológica do Tinguá, localizada na porção centro sul do Estado do Rio de Janeiro, é uma Unidade de Conservação (UC) de proteção integral altamente restritiva em termos de uso e se constitui num relevante fragmento de Floresta Atlântica. No entanto, esta área enfrenta várias pressões como turismo ilegal, caça predatória, extração vegetal, invasões, entre outros. Neste sentido, estudos recentes têm utilizado a percepção ambiental como forma de entender as diferentes relações do ser humano com o meio em que está inserido. A importância da disseminação da temática citada se encontra embasada na Lei 9.985/2000, que rege o Sistema Nacional de Unidades de Conservação (SNUC), já que em seu artigo $5^{\circ}$, estabelece as diretrizes, que em pelo menos três incisos: II, III e V, destacam a necessidade do envolvimento das comunidades locais na gestão dessas áreas.

As Reservas Biológicas visam à preservação integral da biota e demais atributos naturais existentes em seus limites, sem interferência humana direta ou modificações ambientais, excetuando-se as medidas de recuperação de seus ecossistemas alterados e as ações de manejo necessárias para recuperar e preservar o equilíbrio natural, a diversidade biológica e os processos ecológicos naturais (Lei N. ${ }^{\circ}$ 9.985/00, Art N. ${ }^{\circ} 10$ ). Além de ser de domínio público, a visitação é proibida, exceto para pesquisa e atividades que envolvam educação ambiental, desde que devidamente autorizadas pelo órgão competente.

A Reserva Biológica do Tinguá ocupa uma área de 26.260 (ha) com $150 \mathrm{~km}$ de perímetro, e abrange quatro municípios: Nova Iguaçu; Duque de Caxias; Petrópolis; e Miguel Pereira. A maior porção, bem como a sede da Unidade localiza-se em Nova Iguaçu.

Segundo o Plano de Manejo, existem diversos os conflitos na área da UC como o turismo, a caça ilegal, extrativismo vegetal, conflitos com a Petrobras, CEDAE, Furnas e aterros sanitários. Neste sentido os estudos de percepção ambiental (PA) tem se constituído numa importante ferramenta para a compreensão das relações entre os homens e o meio ambiente, evidenciando as interações individualmente ou em grupo. Segundo Oliveira (1996, p. 3), “a percepção é um processo mental de interação do indivíduo com o meio que se dá através de mecanismos perceptivos propriamente ditos e, principalmente, cognitivos".

Compreender a percepção sobre a importância e o valor de uma UC para as pessoas de seu entorno ajuda no entendimento do modo como essa população intervém na área e como é afetada por essa dinâmica. A identificação das distintas percepções contribui para a gestão de conflitos, no planejamento, nas políticas e programas de educação ambiental (HOEFFEL et al., 2008). Permite também a análise de valores, expectativas e interesses das populações locais em relação a uma UC (PACHECO; SILVA, 2006). Possibilita a construção de orientações que subsidiem a tomada de decisões assegurando os objetivos básicos dessas áreas protegidas e a manutenção das condições para uma boa qualidade de vida atual e futura das comunidades envolvidas. 
As UCs não podem ser vistas como limitantes ao desenvolvimento do entorno, mas como promotoras de qualidade de vida para a sociedade. Esse conflito é muito frequente no Brasil, onde problemas sociais básicos (saúde, educação, moradia, alimentação) ainda não foram ou são mal resolvidos. Questiona-se, com frequência, se não é mais importante resolver a problemática social para depois conduzir a agenda ambiental, dentro ou no entorno de uma UC.

Os gestores de UCs, portanto, devem estimular a participação legítima da população local, conduzindo à crítica e possibilidade de transformação social (HOEFFEL et al., 2008). Em muitos casos, as UCs são criadas em um processo de imposição, sem considerar os moradores da região e causando conflitos sociais diversos. Isso gera percepções negativas dos moradores quanto à UC devido à imposição de regras e normas para a conservação, limitando o uso do espaço e as práticas produtivas (PACHECO; SILVA, 2005). Para este autor, no Brasil não há interações positivas entre as instituições de proteção ambiental e as populações do entorno das áreas protegidas. Essa visão precisa ser mudada, a partir do amplo diálogo e participação, pois as UCs são áreas de interesse público e devem ser compreendidas e apoiadas pela sociedade.

Diante do exposto, esta pesquisa, tem como objetivo principal investigar a percepção ambiental dos moradores e demais atores envolvidos incluindo os visitantes que frequentam o local. Foram identificados os principais autores-pesquisadores, conceitos e termos relacionados à percepção ambiental (PA) e unidades de conservação (UC) a partir de leituras exploratórias de textos acadêmicos, livros e capítulos de livros, visando o embasamento teóricometodológico. Por fim, foram aplicados questionários junto à comunidade local.

\section{Materiais e métodos}

Para a elaboração do presente trabalho foram consultadas cerca de 40 fontes bibliográficas (em sua maioria não citadas no presente trabalho), compreendendo livros, capítulos de livros, artigos, teses e dissertações. A partir da análise exploratória desse material, foram destacados os autores mais citados nas bibliografias, seus conceitos e temas relacionados. A pesquisa passa pela Geografia Humanista, Percepção Ambiental, conflitos no entornos das UCs, dentre outros. Como ponto de partida, ressalta-se a dissertação de mestrado da Alessandra Fontana (2004) intitulado: "Ao Redor da Natureza: Investigando a Percepção Ambiental dos Moradores do Entorno da Estação Biológica de Santa Lúcia, Santa Teresa ES".

Num segundo momento foram feitas visitas em campo para reconhecimento da área de estudo e observação, entrevista com o chefe da unidade, formadores de opinião da área apontados por alguns moradores e a ONG Onda Verde. Em sequencia elaborou-se um questionário semiestruturado composto por três grandes blocos: perfil do entrevistado, expectativas em relação à Reserva Biológica (REBIO) e entorno, e o grau de conhecimento sobre a mesma (Figura 01). 
$1^{\circ}$ Fase

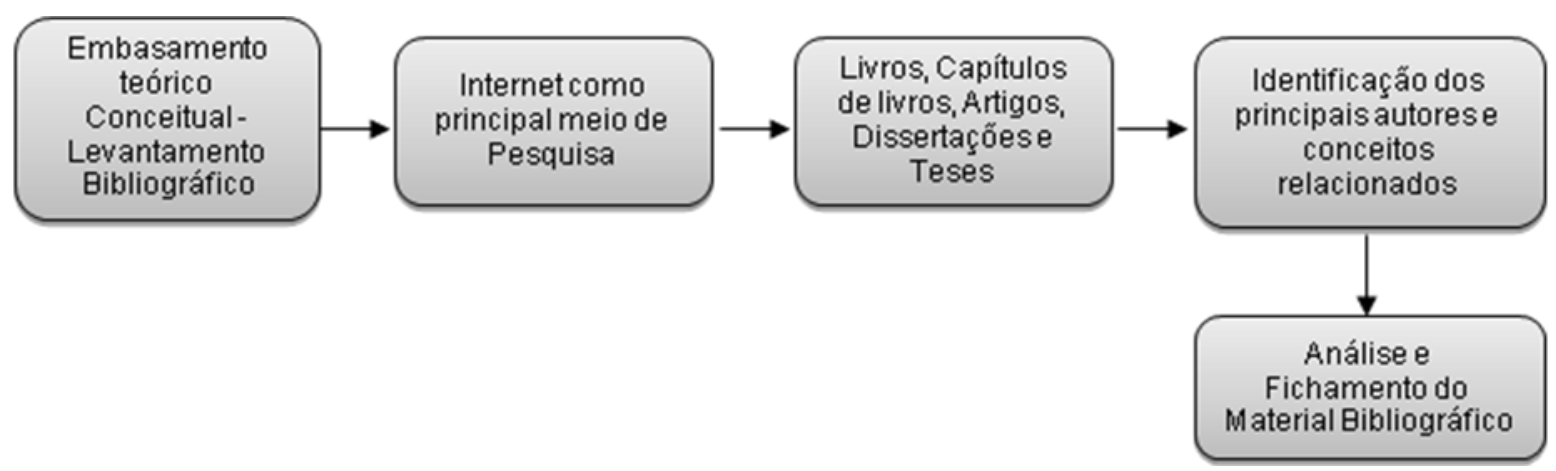

$2^{\circ}$ Fase:

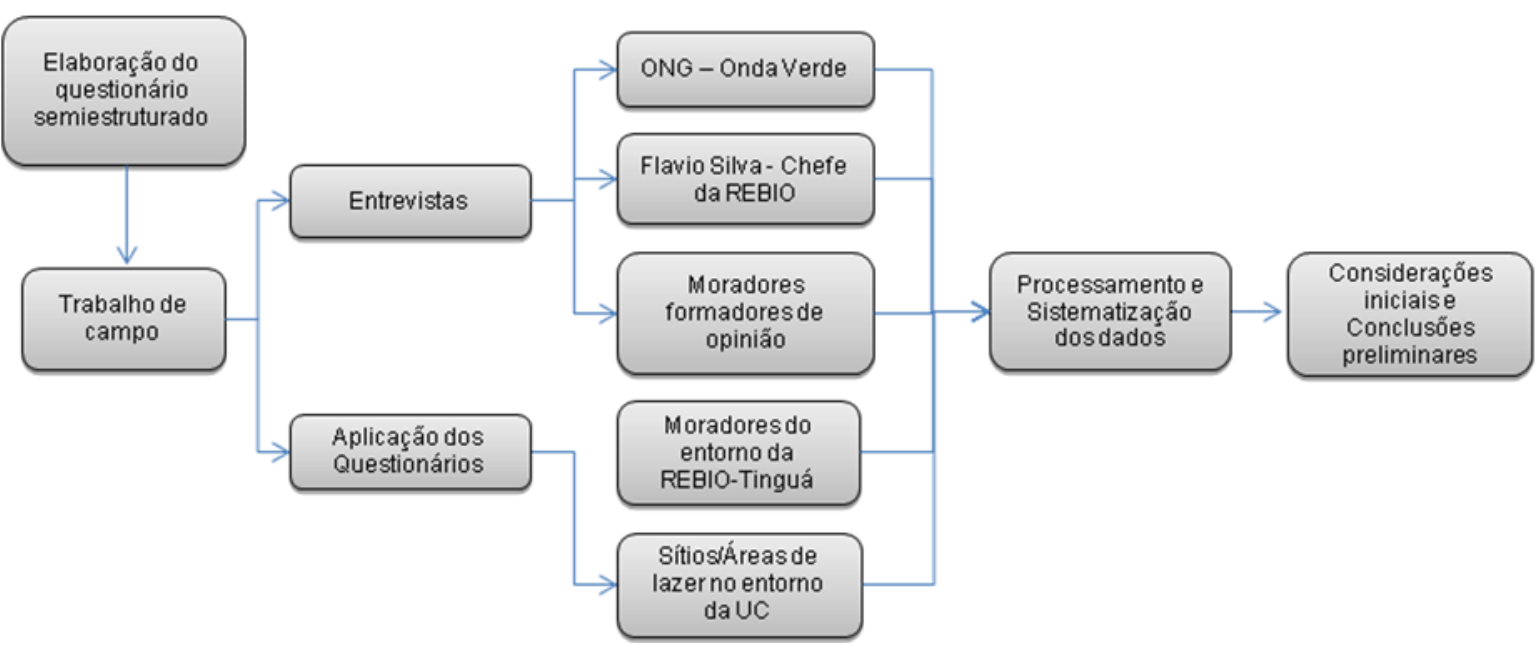

Figura 01. Fluxograma de atividades da pesquisa

\section{Resultados alcançados}

Os resultados abaixo relacionados seguem as etapas da pesquisa: Levantamento Bibliográfico e Entrevistas em Campo

\section{a) Embasamento Teórico Conceitual a partir de Pesquisa Bibliográfica}

Os conceitos foram organizados de acordo com seus autores, sendo os mais citados: YU FU Tuan, geógrafo humanista e considerado precursor no lançamento de conceitos relacionados à Percepção Ambiental (PA); no Brasil, a Geógrafa Lívia de Oliveira foi uma das responsáveis pela introdução dos estudos da percepção do meio ambiente através da Geografia Humanística, na década de 70; e Amorim Filho, que ressalta haver um resgate a partir dos anos 60 dessa maneira de explorar os lugares e paisagens da Terra. Seguem considerações dos três principais autores relacionados à $\mathrm{PA}$, segundo a pesquisa realizada:

YU-FU TUAN - Professor universitário e, desde 1956, viveu sua vida profissional nos Estados Unidos, escreveu dois livros sobre PA: o primeiro intitulado "Topofilia: um estudo da 
percepção, atitudes e valores do meio ambiente". Neste livro, o autor ressalta que precisamos primeiro nos compreender para depois compreender o mundo, que sem a auto compreensão não podemos esperar por soluções duradouras para os problemas ambientais que, fundamentalmente, são problemas humanos, sejam de naturezas econômicas, políticas ou sociais. $\mathrm{O}$ autor estuda os problemas ambientais como um todo, relacionando a complexidade dos problemas com as atitudes e valores humanos. Os conceitos mais trabalhados neste livro são: percepção, atitude, valor, visão do mundo, além do proprio termo que dá título ao livro, este destacado no texto abaixo:

Topofilia é o elo afetivo entre a pessoa e o lugar ou ambiente físico. Difuso como conceito, vivido e concreto como experiência pessoal (Tuan, 1980). Segundo Tuan, a palavra Topofilia é um neologismo, útil quando pode ser definida em sentido amplo, incluindo todos os laços afetivos dos seres humanos com o meio ambiente material. Estes diferem em intensidade, sutileza e modo de expressão (TUAN, 1980, p.107).

Todos estes conceitos se relacionam: a percepção está ligada a cultura, o indivíduo percebe de acordo com o que ele vive. As sociedades podem ver o mundo de maneiras diferentes de acordo com as suas necessidades (TUAN, 1980, p. 91). As atitudes ambientais compõem um conjunto de percepções que, por sua vez, estão diretamente relacionadas com a cultura e a experiência de cada indivíduo. Este autor ressalta que todos os seres humanos compartilham percepções comuns, um mundo comum, em virtude de possuírem órgãos similares, apesar de duas pessoas não verem a mesma realidade; nem dois grupos sociais fazem a mesma leitura do meio ambiente.

LÍVIA DE OLIVEIRA - Professora do Departamento de Geografia da UNESP - Rio Claro, pioneira da Geografia Humanista no Brasil e PA, conceito que ela acha limitado e prefere chamar de Percepção do Meio Ambiente. Foi a partir das leituras e tradução dos livros de YIFU Tuan (Topofilia, 1980) e (Espaço e Lugar, 1983), que a professora difundiu esses conceitos no Brasil, sendo Tuan o grande referencial desta linha de pesquisa. Junto com outros nomes orientou trabalhos sobre a geografia humanista e percepção ambiental. Interessou-se por Piaget quando já era professora da UNESP é diz ser impossível ensinar geografia sem o conhecer (Marandola Junior, 2003).

OSWALDO BUENO AMORIM FILHO - Professor de Geografia na UFMG e do Programa de Pós-Graduação em Geografia pela PUC-MG, pesquisador na linha da Geografia Humanista e Cultural. É o terceiro autor que mais aparece nas bibliografias exploradas sobre a temática. Ele ressalta que a Geografia Humanista possui raízes antigas, apesar de ser um campo novo de estudo. Amorim Filho relembra que nos anos 60 existiam duas correntes de orientações epistemológicas: de um lado a qualificação, a racionalização e a sistematização dos neopositivistas; de outro, o materialismo e o economismo dos neo-marxistas. Eram duas correntes extremas e para contrapor às duas, surgiu na década de 70 a Geografia Humanística, priorizando não só o objetivo ou teórico, mas o ser humano de uma maneira geral, com as suas percepções, representações, atitudes e valores.

Amorim Filho, na sua pesquisa intitulada: "Os Estudos da Percepção Como Última Fronteira da Gestão Ambiental", trata de conceitos e técnicas fundamentais para o estudo da 
percepção, que teve a retomada de alguns termos tradicionais da atividade geográfica. $\mathrm{O}$ autor selecionou dez conceitos baseados na frequência e regularidade que vem sendo utilizados nas pesquisas de percepção, alguns já citados. São eles: atitude; cognição; imagem; paisagem; percepção; representação; valor; Topocídio; Topofilia; Topofobia.

O autor destaca que o conceito de Topocídio é de grande significado para o futuro do meio ambiente e este estranha que se tenha demorado tanto para se chegar a ele, pois há muito se causam danos, muitas vezes irreversíveis aos lugares, às paisagens, aos espaços vividos e às porções significativas da natureza. Quando se alcançar a tomada de consciência da gravidade desses danos causados ao meio ambiente, natural ou construído, o Topocídio receberá a atenção e talvez, a punição que merecem todos os ilícitos graves (AMORIM FILHO, 1996).

Foi a partir daí que o conceito de Topo-reabilitação surgiu (AMORIM FILHO, op. cit.), sendo usado no sentido de reabilitar uma área que sofreu com o Topocídio. Esse conceito traz a ideia de se reverter as ações destrutivas que aconteceram numa determinada área, ajudando na recuperação do meio ambiente. Para a melhoria da qualidade de vida dos homens, manutenção da sua memória coletiva ou individual e preservação da sua identidade cultural e seus valores, é necessário que as forças da topo-reabilitação superem as forças topocídicas em todo o mundo. Segundo o autor, este é um dos maiores desafios da humanidade nesta passagem de milênio.

\section{b) Entrevistas}

A porção do entorno da REBIO Tinguá que abrange o município de Nova Iguaçu compreende as localidades de Tinguá, Rio D’Ouro, Adrianópolis e Jaceruba. Nesta fase, as entrevistas foram realizadas com 62 moradores da vila do Tinguá. Destes, 36 são do sexo feminino e 26 do sexo masculino. A faixa etária predominante é de 35 a 50 anos, com $34 \%$ das respostas (Figura 02). Quanto à escolaridade, 45\% têm o nível fundamental, 47\% o nível médio e 5\% nível superior. Três pessoas responderam não ter escolaridade (Figura 03).

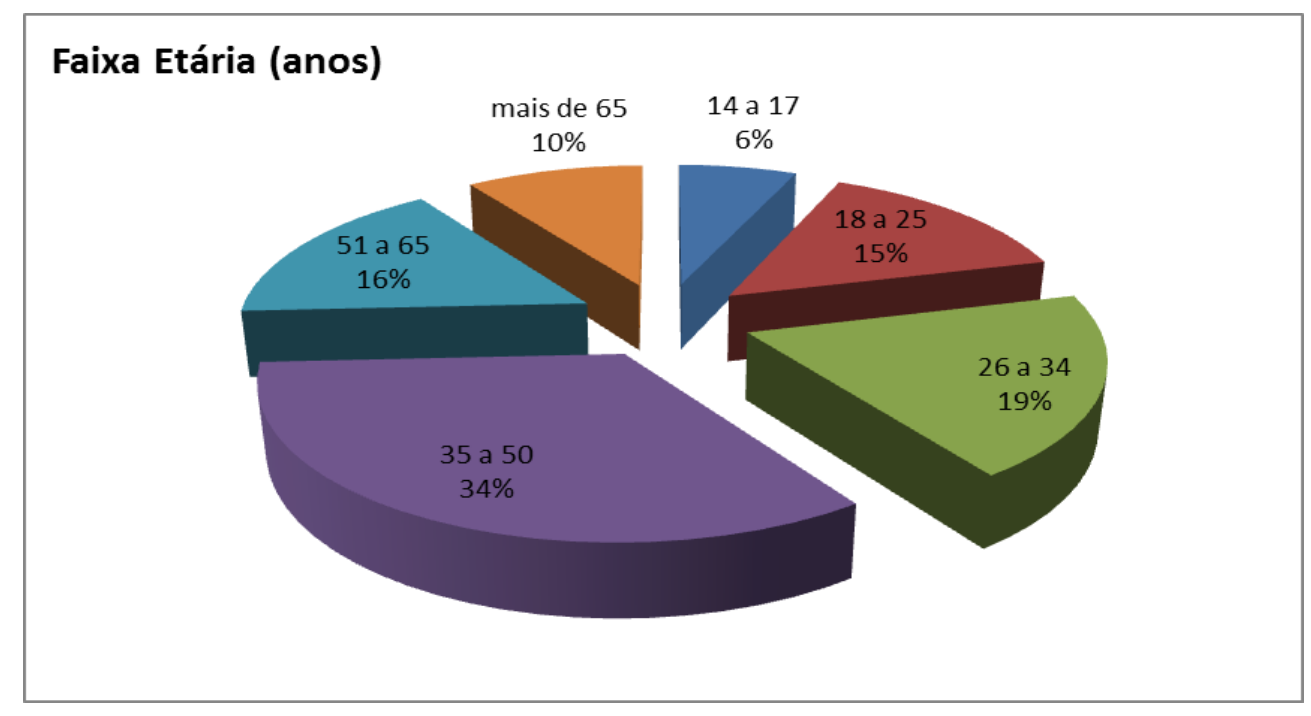

Figura 02. Faixa etária dos moradores entrevistados. 


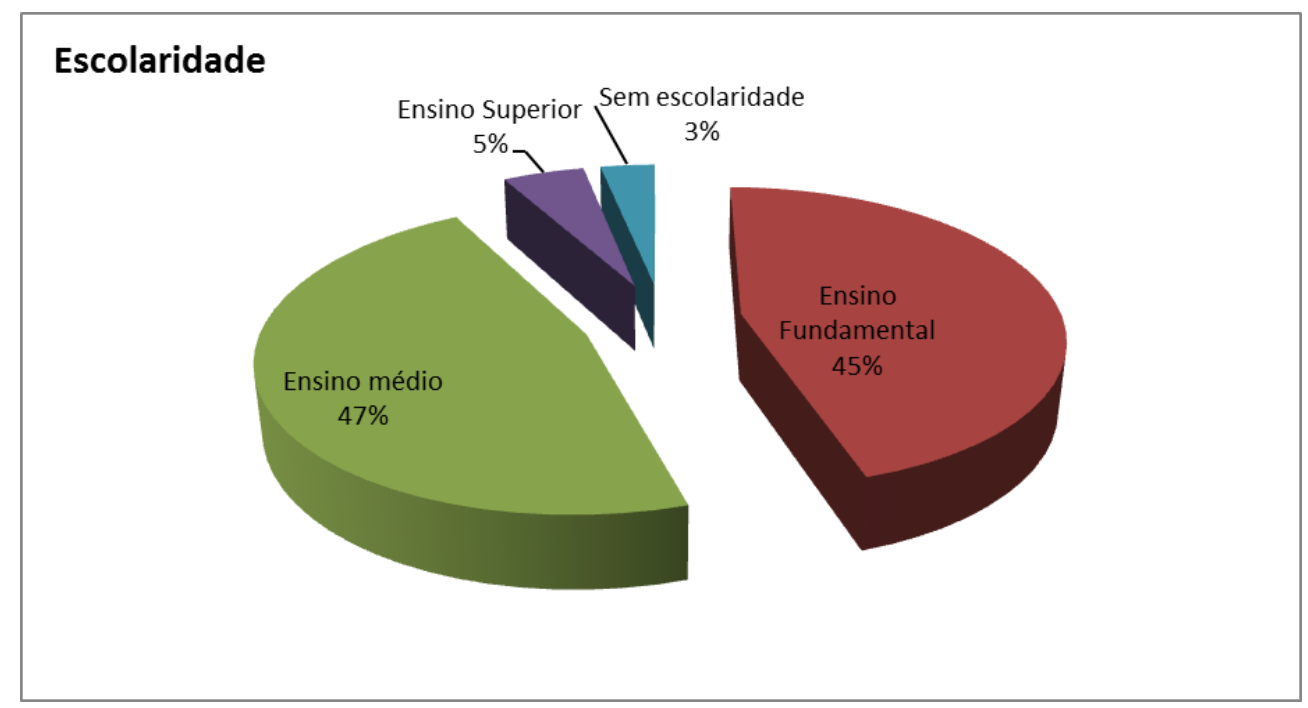

Figura 03. Escolaridade dos moradores entrevistados.

Sobre a dinâmica de utilização da área, 90\% responderam que a REBIO - Tinguá é importante em sua vida, relacionando frequentemente a presença da UC com tranquilidade, qualidade de vida e ar puro. Neste quesito seguem algumas considerações:

A REBIO é a preservação da natureza, ela não é importante na sua vida, pois é "sobrevivência para a vida". A natureza simboliza a vida, traz água, chuva e ar.

"Quem deve cuidar da REBIO é o ICMBio, eu cuido recolhendo o lixo, mesmo não sendo meu, e tento educar as pessoas, como por exemplo para não mergulharem na adutora. O principal problema é a falta de fiscalização, $e$ deve ser melhorada a assistência das autoridades. Eu moro na região e pretendo continuar morando, se eu sair daqui sou um peixe fora do aquário (...). Morador do entorno da REBIO-Tinguá, 2013, entrevista.

O mesmo morador ressalta que há um abuso por parte dos cultos religiosos: diz entender e respeitar, mas não aprecia ver seu bairro com oferendas, acha que: o certo seria criar um "macumbódromo para que fizessem as oferendes e depois limpassem”, quanto aos evangélicos diz que "sobem ao monte e deixam lixo pelo caminho, poderiam recolher o seu lixo".

Quanto às expectativas de vida em relação à região do entorno da REBIO Tinguá, 50\% dos entrevistados moram na região e pretendem continuar morando; $31 \%$ acreditam que a região pode melhorar e apenas $13 \%$ moram e pretendem ir embora (Figura 04). 


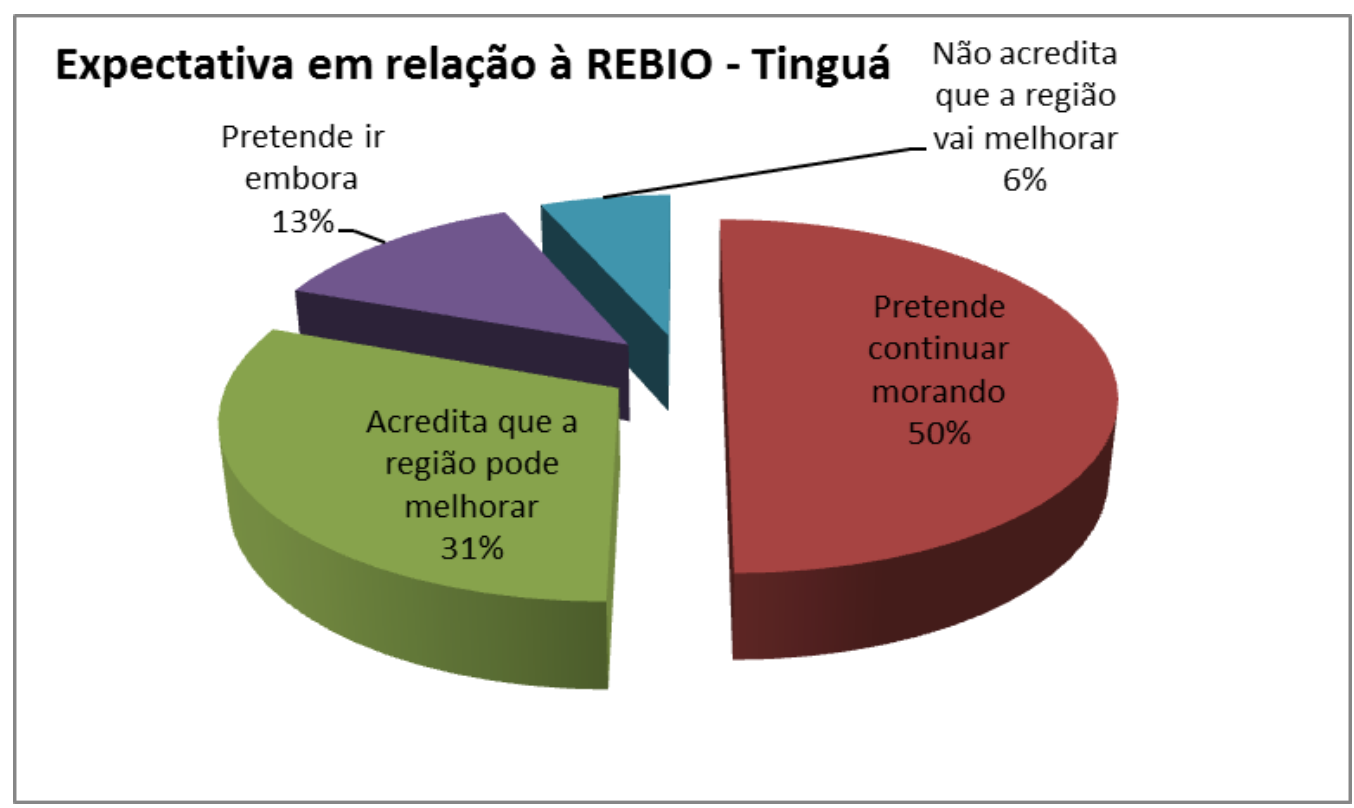

Figura 04. Expectativa dos moradores em relação à REBIO - Tinguá

Segundo um visitante: "A região pode melhorar, mas seria bom que guardassem a natureza, pois o aumento de infraestrutura pode deteriorar toda área geográfica." (morador de Mesquita, município vizinho à Nova Iguaçu, 2013).

Já um técnico ambiental da REBIO Tinguá, afirma que, para que essa melhora aconteça é preciso que seja fortalecida a participação coletiva, e ressalta ainda que: "A inexistência de uma relação harmônica entre os atores sociais, acaba atrasando planos e projetos".

Para um comerciante local a fiscalização deveria ser mais intensa, e que deveria ser feito projetos ambientais voltados para os caçadores, pois para ele "a educação norteia tudo, seja na reserva, em casa ou na vida".

Em relação ao principal problema da região, $60 \%$ responderam ser o lixo. Neste aspecto, torna-se importante citar que o período de aplicação dos questionários compreendeu a transição em termos de gestão municipal, assim o contrato da empresa responsável pela coleta do lixo não havia sido renovado, causando transtornos à população local. Acrescenta-se que 18 $\%$ apontaram a falta de fiscalização como um dos principais problemas; e no quesito outros, os moradores geralmente relacionavam à carência de infraestrutura, como posto de saúde e transporte público (Figura 05), ambos de competência municipal. 


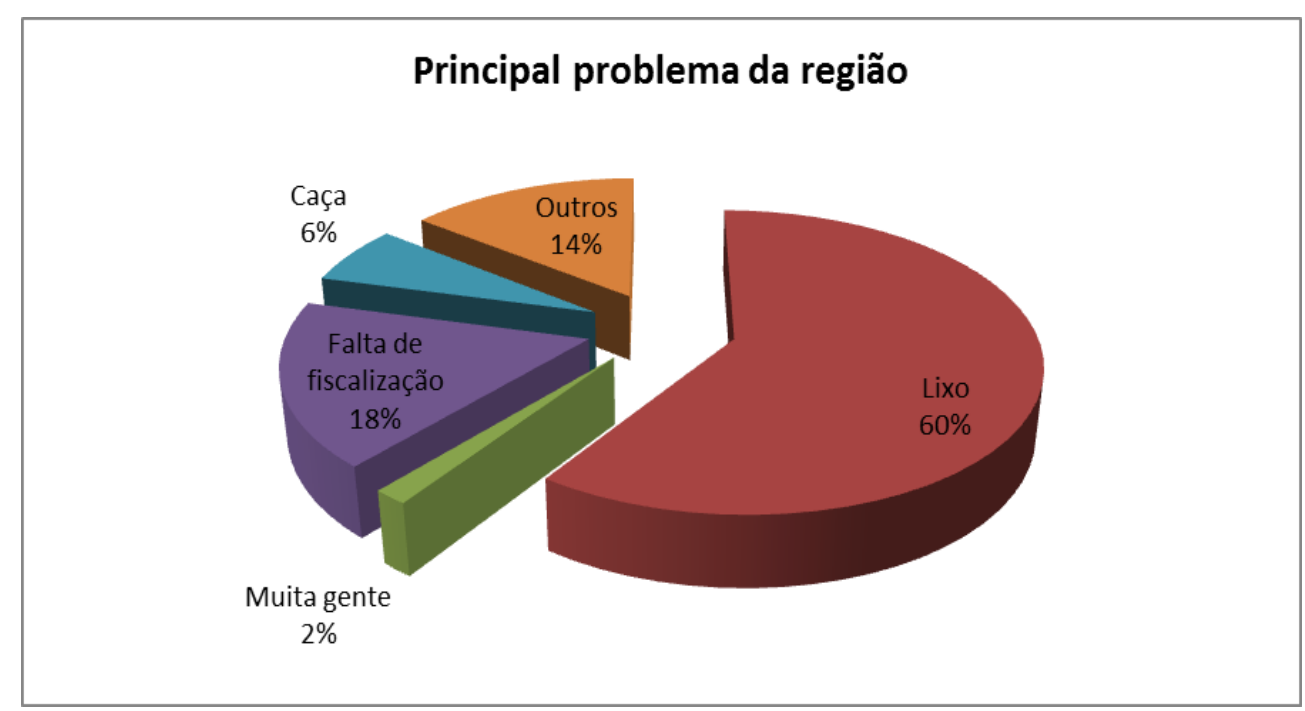

Figura 05. Principal problema da região da vila do Tinguá apontado pelos moradores

\section{Conclusões}

O estudo da Percepção Ambiental (PA) prioriza o homem como sujeito, partindo da visão do indivíduo para entender a realidade local, que faz parte da subjetividade de cada sujeito. Esses estudos associados às ações de Educação e Interpretação Ambiental podem auxiliar na gestão de Áreas Protegidas, buscando minimizar conflitos e estimular junto as comunidades envolvidas a aproximação, o sentimento de pertencimento e de valorização dessas áreas.

Nas entrevistas realizadas com os moradores do entorno da REBIO Tinguá foi possível avaliar preliminarmente a percepção sobre a Reserva, além das expectativas de vida em relação ao lugar. Ficou evidente que não percebem esta UC como algo negativo para as suas vidas, muito pelo contrário, $90 \%$ dos entrevistados entendem ser importante, entretanto, os resultados indicaram que os moradores não conseguem discernir exatamente as competências de gestão, apontando como um dos principais problemas a carência em termos de infraestrutura, principalmente quanto a um posto de saúde, geralmente de gestão municipal.

Esta visão positiva sobre o ambiente da REBIO e a valorização da qualidade de vida que advém da preservação da floresta pode e deve se tornar aliada na gestão da REBIO. Constatou-se também a necessidade de uma aproximação junto à comunidade, sugerindo-se a realização periódica de visitas monitoradas voltadas somente para os moradores do entorno da Reserva de modo a estimular nestes o sentimento de pertencimento.

\section{Agradecimentos}

Em primeiro lugar ao gerente da REBIO Tinguá Flavio Silva pelo seu apoio, igualmente aos professores Orientadores Mauro Guimarães e Camila Rodrigues por acreditarem no potencial deste trabalho de pesquisa; aos alunos da Turma 2012.1 do Curso de Turismo da UFRRJ pelo auxílio nos trabalhos de campo e ao CNPq e à FAPERJ pela concessão de bolsas de Iniciação Científica. 


\section{Referências bibliográficas}

\section{AMORIM FILHO, O. B. Os Estudos da Percepção como a Última Fronteira da Gestão}

Ambiental. Disponível em: <http://www.sites.uol.com.br/ivairr/percepcaoambi.htm>. Acesso em: nov. 2012 Topofilia, Topofobia e Topocídio em Minas Gerais - In: DEL RIO,

V.; OLIVEIRA, L. Percepção Ambiental: a Experiência Brasileira. São Paulo: Studio Nobel, 1996. p. 139-152.

FONTANA, A. Ao Redor da Natureza: Investigando a Percepção Ambiental dos Moradores do entorno da Estação biológica de Santa Lúcia, Santa Teresa - ES. - Dissertação (Mestrado em Antropologia)- Departamento de Antropologia/EICOS, Universidade Federal do Rio de Janeiro, Rio de Janeiro, 2004.

HOEFEL, J.; MORAES, L. Trajetórias do Jaguary : unidades de conservação, percepção ambiental e turismo. Um estudo na APA do Sistema Cantareira. 2009.

OLIVEIRA, L. Percepção e Representação do Espaço Geográfico; In: DEL RIO, V.;

OLIVEIRA, L.Percepção Ambiental: uma experiência brasileira. São Paulo: Studio

Nobel,1996. p. 187-214.

PACHECO, E.; SILVA, H. P. Compromissos Epistemológicos do Conceito de Percepção Ambiental. Rio de Janeiro: Departamento de Antropologia. EICOS/ UFRJ.

PLANO DE MANEJO Da Reserva Biológica do Tinguá. Brasília, 2006.

Sistema Nacional de Unidades de Conservação (SNUC). LEI N. ${ }^{\circ} 9.985$, de 18 de julho de 2000. Brasília, 2000.

TUAN, YU-FU. Espaço e Lugar: a Perspectiva da Experiência. OLIVEIRA, L (Trad.). Rio Claro,SP: Editora da UNESP, 1983.

. Topofilia: Um Estudo da Percepção, Atitudes e Valores do Meio Ambiente.

OLIVEIRA, L (Trad.). Rio Claro, SP: Editora da UNESP, 1980. 